\title{
New Development of Intelligent Well Completion Technology in Oil Industry
}

\author{
Jianbo Hu, Yifeng Di, Qisheng Tang, Ren Wen, Hanjie Liu
}

Tianjin Branch of CNOOC Ltd.

\begin{abstract}
With the continuous expansion of oil and gas exploration and development, there are more and more special oil and gas reservoirs such as desert and deep sea, and the oil and gas storage environment is becoming more and more complex. In order to develop these reservoirs effectively, special structure wells such as horizontal wells, large displacement wells and multi-branch wells are being used more and more extensively, and the number is increasing. How to optimize the completion method and production management process of these special structure wells has become an urgent problem in oil and gas production in China. However, the traditional completion methods and production management mode can no longer meet the needs of production management and optimization of special structure wells. The research and development of intelligent completion systems and related technologies in recent years have provided a solution to this problem and gradually changed the production management mode of oil and gas wells.
\end{abstract}

Keywords: Intelligent well completion, Research progress, Technology.

\section{Introduction}

The Intelligent Well (IW) system was first successfully installed in the Norwegian oilfield in 1997[1]. The system consists of three major components: real-time production monitoring, real-time regulation and control, and production prediction and optimization. processing, analyzing data characteristics, applying reservoir auto-fitting and reservoir numerical simulation and prediction techniques, optimizing to get the best intelligent oilfield development plan, and adjusting downhole control valves in real time through feedback mechanism, so as to increase the production of oil wells and improve the recovery rate of oil reservoirs [2-3].

The smart completion tubulars are installed in the borehole by "one shot drilling", and there is no need to go downhole again to install the completion tubulars at the bottom of the borehole. This "one-trip drilling" method of installing the entire completion tubing avoids the need to lower the coupling in the borehole when installing the completion tubing in "multiple trips". In addition, the "one-trip" completion column installation ensures the continuity and integrity of the control cables in the borehole and allows the column to be tested as a whole after the installation is completed. The smart completion tubulars use special pressure and temperature sensors that are installed inside the borehole in each section of the well [4].

\section{The Features of Intelligent Completion Technology}

The main function of intelligent completion is to conduct long-term downhole real-time monitoring of reservoir performance and obtain a large number of reservoir parameters so that reservoir managers can flexibly control the production of oil and gas flow in each section of single wells with multiple oil layers and multi-branch wells, or even control the entire oilfield well network to maximize well production; substantially improve reservoir management, reduce oil recovery costs and improve the economic efficiency of well production Optimize the production of oil wells and reduce the large number of well repair operations required during production, i.e., minimize operating costs and production risks while maximizing the recovery rate of the oil formation. Although intelligent wells do not mean that the production system has the ability to control or optimize production automatically, they still require a manual interface to issue commands to control the producing wells, but they provide a more intelligent, flexible and efficient form of management for oil resources and oil production, and are receiving more and more attention and will become an important technology for the oil industry in the 21 st century.

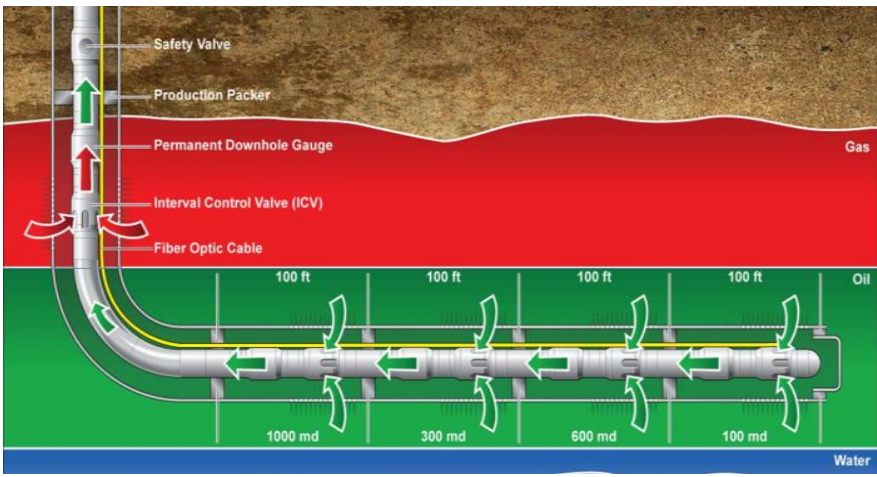

Figure 1: The Basics of an Intelligent Completion

\section{Status of Intelligent Completion Technology Development}

Since the introduction of intelligent completion technology in the 1970s, the development of this technology has progressed by leaps and bounds. The development of this technology can be divided into the following four stages: (1) the budding period of intelligent completion technology: this stage lacks the necessary downhole monitoring equipment and mainly relies on the experience of production operators to switch on and off the downhole flow blocking valve to achieve reservoir stratification; (2) the development period of intelligent completion technology: this stage allows production operators to achieve surface monitoring and control through permanent downhole (2) Intelligent Completion Technology 
Development Period: During this period, production operators can achieve surface monitoring and control through permanent downhole electronic measurement devices, but still lack software support and can only operate through staff experience; (C3) Intelligent Completion Technology Maturity Period: During this period, major oilfield service companies have successfully developed different types of completion technology supporting software, and intelligent completion technology integration has been realized for industrial application; (4) Intelligent Completion Technology Transformation Period: During this period, downhole detection devices gradually changed from Permanent electronic measuring device to fiber optic sensing development.

Although there is no intelligent completion system in China, some progress has been made in the process technology of stratified injection and segmented completion, packers, and long-term monitoring of downhole data. After years of scientific research and development, Shengli Oilfield has achieved some milestones in intelligent well completion: the overall performance of the developed high-strength compressed tubular packer is close to the level of similar foreign products, and the oil and water self-expanding tubular packer can meet the requirements of field applications; the formation of balanced fluid supply sieve tube segmentation completion technology and data acquisition technology has been applied 50 times. The mathematical model for processing downhole fluid production and pressure data has been established, and the model can determine the water formation level based on the processing results; the method of using the mathematical model for processing downhole fluid production and pressure to determine the water formation level has been verified through the simulation test of screen tube segment completion data acquisition.

\section{Intelligent Well Components}

The intelligent well system mainly includes: (1) Downhole information collection sensing system: It consists of a series of permanent sensors installed in the well, including displacement, pressure, flow rate, temperature and other types of sensors; (2) Downhole flow control system: The downhole flow control system can remotely control the flow rate of each production layer and is the key equipment of the entire intelligent well system. The control methods of the downhole flow control system mainly include electric drive, hydraulic drive and electric-hydraulic hybrid drive, and the flow controller of each production layer is separated by a packer: (shown in Figure 2, 3) (3) Downhole data transmission system: It is the link between the downhole information collection system and the surface information processing and control system, and can transmit the information collected from the downhole to the surface through a permanent cable (Figure 4). The computer is used to collect and store the information collected downhole and transmitted to the surface, and then the data is analyzed by special data analysis equipment to control the entire intelligent well system and optimize production.

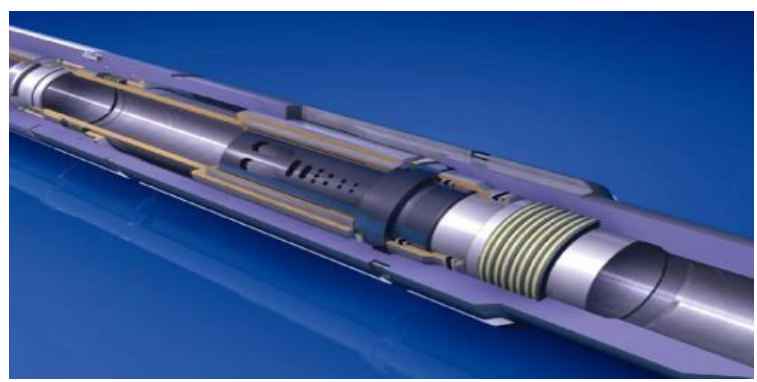

Figure 2: Downhole Flow Control Valves

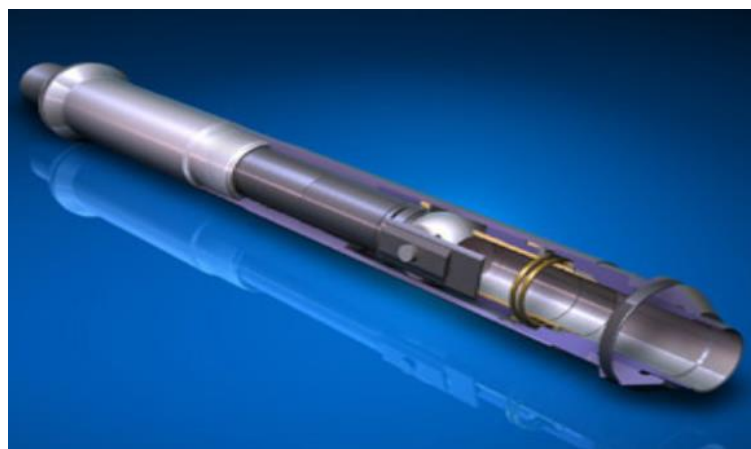

Figure 3: Lubricator Valve (LV-ICV)

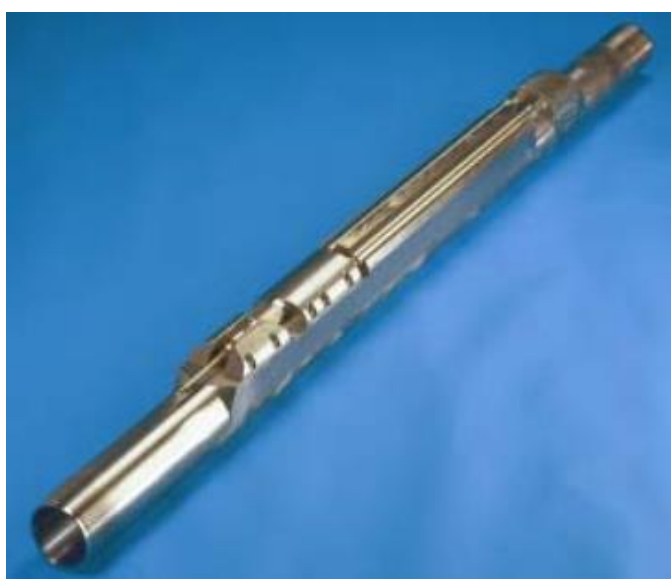

Figure 4: Permanent Downhole Gauges

\section{Conclusion}

Smart well technology is an emerging well production management technology and an important part of smart oilfield. It is a real-time injection and production control network with the ability to collect, transmit, and analyze borehole production data, reservoir data, and completion data without the need for workover operations. The main goal of an intelligent well completion system is to improve well recovery while minimizing the cost and risk of extraction, thereby improving the overall economic efficiency of the field. Smart well systems are suitable for field environments where well workovers are expensive, such as offshore wells, deepwater wells, and desert wells.

\section{References}

[1] Sheng leixiang, Xu Liangbin, Jiang Shiquan, Zhou Jianliang, he Dongsheng. Design of hydraulic control system for intelligent completion downhole flow valve [J]. Petroleum mining machinery, 2012, 41 (04): 34-38.

[2] Yu Jinling, Wei Xinfang. New research progress of intelligent well completion technology in Shengli 
Oilfield [J]. Petroleum drilling technology, 2011, 39 (02): 68-72.

[3] Ruan Chenliang, Zhu Heming, Feng Liying. Introduction to foreign intelligent well completion technology [J]. Petroleum machinery, 2011, 39 (03): 82-84.

[4] Xu Sheng, Chen Yilei, Yang Yuankun, Nan Jinhu. Research status and application prospect of intelligent well downhole instruments [J]. Petroleum instruments, 2011, 25 (01): 46-48.

[5] Qu Congfeng, Wang Zhaohui, Yuan Jinping. Development status and trend of intelligent well completion [J]. Foreign Oilfield Engineering, 2010, 26 (07): 28-31.

[6] Wang Zhaohui, Qu Congfeng, Yuan Jinping. Key technology analysis of intelligent well completion system $[\mathrm{J}]$. Petroleum drilling and production technology, 2009, 31 (05): 1-4.

[7] Yang Liping. Current situation and development trend of offshore oil completion technology [J]. Oil drilling and production technology, 2008 (01): 1-6.

[8] Yuan Jinping, Qi Fengzhong. Current situation of domestic well completion technology and suggestions on research direction [J]. Drilling and production technology, 2007 (03): 3-6.

[9] Xiao Shuqin, Chen Junbin, Qu Zhan. Intelligent well completion integrated system [J]. Journal of Xi'an University of Petroleum (Natural Science Edition), 2004(02): 37-40. 